\title{
Macroscopic Photoinduced and Reversible Sol-Gel Conversions of Polymer Materials Containing Photoreactive Coumarin Moieties
}

\author{
Masaya Moriyama ${ }^{1 *}$, Takumi Okano ${ }^{1}$, Shohei Ono ${ }^{1}$, Sakurako Nagano ${ }^{1}$, \\ Nobuyoshi Shirieda ${ }^{1}$, and Kazuhiro Yabuuchi ${ }^{2}$ \\ 1 Department of Applied Chemistry, Faculty of Engineering, Oita University, 700 Dannoharu, Oita, 870-1192. \\ 2 Department of Applied Chemistry, College of Engineering, Chubu University, 1200 Matsumoto-cho, Kasugai, Aichi 487-8501. \\ * Corresponding author: Fax: 81-97-554-7897, and/or e-mail: morimasa@oita-u.ac.jp
}

\begin{abstract}
Hydrophilic copolymers containing $N$-isopropylacrylamide and acrylate with coumarin or 4-methylcoumarin moieties have been synthesized. We reveal that the copolymers with a very small content of coumarin and 4-methylcoumarin units exhibit macroscopic photoinduced and reversible sol-gel conversions. UV light $(\lambda>310 \mathrm{~nm})$ irradiation of aqueous solutions for the copolymers causes the increase in viscosity and the formation of hydrogels, based on photodimerization of coumarin moieties. Subsequent irradiation with UV light $(\lambda=254 \mathrm{~nm})$ of the hydrogels induces the return of fluidity and the change to sol state, due to the decomposition of coumarin dimers. The amount of crosslink structures in the copolymers can be regulated by the reversible photoreaction of coumarin moieties.
\end{abstract}

Key words: Polymer gel, Photoinduced sol-gel conversion, Coumarin, Photodimerization, Photocrosslink

\section{INTRODUCTION}

General synthetic polymer materials are constructed of monomer units by covalent bonds. Therefore, bond cleavage and reconstruction cannot be caused easily in general conditions. Coumarin, a lactone obtained by intramolecular cyclization of cinnamate, is one of the fascinating photofunctional molecules. It is widely used as a laser dye and biomolecular marker, because of its superior fluorescent property. Moreover, the coumarin structures were widely employed as antioxidant in natural products. On the other hand, coumarin causes reversible photodimerization and photocleavage reactions. Upon photoirradiation of coumarin at $\lambda>300$ $\mathrm{nm},[2+2]$ cycloaddition occurs between two coumarin molecules and a cyclobutane structure forms. Subsequent irradiation of the coumarin dimer at $\lambda<300$ $\mathrm{nm}$ induces cleavage of the cyclobutane ring and the monomer coumarins reform. Various coumarin-functionalized polymer materials, in particular, photo-cross-linking polymers have been reported thus far[1-14]. Chujo et al. reported photocontrollable swelling behavior of hydrogel films obtained from polyoxazoline having a coumarin moiety[1]. Zhao et al. reported photoinduced size change of nanogels composed of hydrophilic block copolymers containing coumarin moieties. Most of these researches employed film-type gels on a substrate or microscopic gels for the examination of their swelling properties[2-6].

Here, we have synthesized the copolymers composed of an acrylate monomer with a coumarin (A6C) or a 4-methylcoumarin moiety (A6MC) and $N$-isopropylacrylamide (NIPAM), and demonstrated the macroscopic photoconversions (Fig. 1) and introduce macroscopic, photoinduced, and reversible sol-gel conversions of their coumarin-containing copolymers.

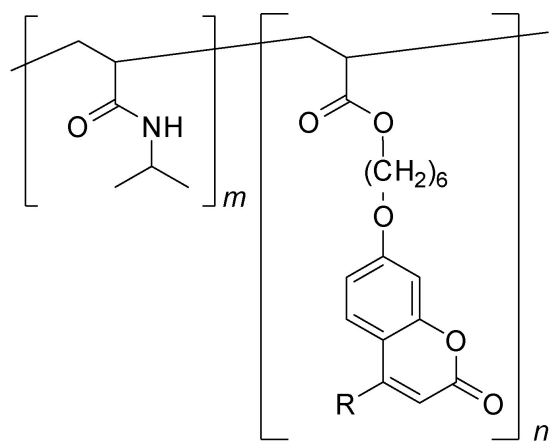

P(NIPAM ${ }_{100}-$ Co- $\left.^{-A_{6} C_{0.3}}\right): \mathrm{R}=\mathrm{H}, m: n=100: 0.3$

$\mathbf{P}\left(\right.$ NIPAM $_{100}-$ Co-A6MC $\left._{0.3}\right): \mathrm{R}=\mathrm{CH}_{3}, m: n=100: 0.3$

P(NIPAM ${ }_{100}-$ Co-A6MC $\left._{1}\right): R=\mathrm{CH}_{3}, m: n=100: 1$

Fig.1 Molecular structures of hydrophilic copolymers synthesized in this study.

\section{EXPERIMENTS}

2.1 Materials

7-Hydroxycoumarin (umbelliferone), 7-hydroxy4-methylcoumarin (4-methylumbelliferone), 6-chlorohexanol, acryloyl chloride, 2,2'-azobisisobutyronitrile (AIBN), potassium carbonate $\left(\mathrm{K}_{2} \mathrm{CO}_{3}\right)$, potassium iodide (KI), tetrahydrofuran (THF), N,N'-dimethylformamide (DMF), dimethylsulfoxide (DMSO), ethyl acetate, chloroform, and diethylether were purchased from Wako Pure Chemical Industries, Ltd and used as received. $\mathrm{N}$-isopropylacrylamide (NIPAM) was purchased from Wako and used after recrystallization from hexane. 
7-(6-Hydroxyhexyloxy)coumarin and 7-(6-hydroxyhexyloxy)-4-methylcoumarin were synthesized according to the literatures[15,16].

\subsection{Syntheses}

\section{7-(6-(Acryloyloxy)hexyloxy)coumarin (A6C)}

A solution of acryloyl chloride $(0.34 \mathrm{~g}, 3.8 \mathrm{mmol})$ in THF was added to the solution of 7-(6-hydroxyhexyloxy)coumarin $(1.0 \mathrm{~g}, 3.9 \mathrm{mmol})$, triethylamine $(0.42 \mathrm{~g}, 4.2 \mathrm{mmol})$ in THF. The reaction mixture was stirred at room temperature for $25 \mathrm{~h}$. After the reaction, the product was extracted with chloroform and washed with water and brine. Chloroform was evaporated under reduced pressure. The crude product was purified by column chromatography on silica gel with chloroform/ethyl acetate (4/1). White solid $(0.59 \mathrm{~g}, 1.9$ mmol, $48 \%$ yield) was obtained. $\mathrm{mp}: 53-54{ }^{\circ} \mathrm{C}$. ${ }^{1} \mathrm{H}-\mathrm{NMR}\left(400 \mathrm{MHz}, \mathrm{CDCl}_{3}\right): \delta 7.64(\mathrm{~d}, 1 \mathrm{H}, J=9.4 \mathrm{~Hz}$, aromatic), $7.36(\mathrm{~d}, 1 \mathrm{H}, J=8.6 \mathrm{~Hz}$, aromatic), 6.85-6.80 (m, $2 \mathrm{H}$, aromatic), $6.41(\mathrm{dd}, 1 \mathrm{H}, J=17.3$ and $1.5 \mathrm{~Hz}$, ethylene), $6.25(\mathrm{~d}, 1 \mathrm{H}, J=9.4 \mathrm{~Hz}$, aromatic), 6.13 (dd, $1 \mathrm{H}, J=17.3$ and $10.4 \mathrm{~Hz}$, ethylene), 5.83 (dd, $1 \mathrm{H}, J=$ 10.4 and $1.5 \mathrm{~Hz}$, ethylene), $4.18\left(\mathrm{t}, 2 \mathrm{H},-\mathrm{COOCH}_{2}-\right)$, $4.02\left(\mathrm{t}, \quad 2 \mathrm{H}, \quad-\mathrm{PhOCH}_{2}-\right.$ ) 1.84 (quint, $2 \mathrm{H}$, $-\mathrm{COOCH}_{2} \mathrm{CH}_{2}-$ ), 1.72 (quint, 2H, $-\mathrm{PhOCH}_{2} \mathrm{CH}_{2}-$ ), 1.53-1.46 (m, 4H, $\left.-\mathrm{CH}_{2} \mathrm{CH}_{2} \mathrm{CH}_{2} \mathrm{CH}_{2}-\right)$ ppm. ${ }^{13} \mathrm{C}-\mathrm{NMR}$ $\left(100 \mathrm{MHz}, \mathrm{CDCl}_{3}\right): \delta 166.3,162.3,161.3,155.9,143.4$, 130.6, 128.7, 128.6, 113.0, 112.4 101.3, 68.4, 64.4, 28.9, 28.5, 25.7, $25.7 \mathrm{ppm}$. Anal. Calcd for $\mathrm{C}_{18} \mathrm{H}_{20} \mathrm{O}_{5}$ : C, 68.34; H, 6.37. Found: C, 68.34; H, 6.44.

\section{7-(6-(Acryloyloxy)hexyloxy)-4-methylcoumarin (A6MC)}

7-(6-hydroxyhexyloxy)-4-methylcoumarin (2.0 g, 7.3 $\mathrm{mmol}))$, triethylamine $(1.0 \mathrm{~g}, 10 \mathrm{mmol})$ in THF. The reaction mixture was stirred at room temperature for $22.5 \mathrm{~h}$. After the reaction, product was extracted with chloroform and washed with water and brine. chloroform was evaporated under reduced pressure. The crude product was purified by column chromatography on silicagel with chloroform/ethyl acetate $4 / 1$ and washed with diethylether. White solid $(1.1 \mathrm{~g}, 3.2 \mathrm{mmol}$, $44 \%$ yield) was obtained. mp: $55-56{ }^{\circ} \mathrm{C} .{ }^{1} \mathrm{H}-\mathrm{NMR}(400$ $\left.\mathrm{MHz}_{\mathrm{CDCl}}\right): \delta 7.49(\mathrm{~d}, 1 \mathrm{H}, J=8.8 \mathrm{~Hz}$, aromatic), 6.85 (dd, $1 \mathrm{H}, J=8.8$ and $2.5 \mathrm{~Hz}$, aromatic), $6.80(\mathrm{~d}, 1 \mathrm{H}, J=$ $2.5 \mathrm{~Hz}$, aromatic), $6.40(\mathrm{dd}, 1 \mathrm{H}, J=17.3$ and $1.5 \mathrm{~Hz}$, ethylene), 6.16-6.09 (m, 2H, aromatic and ethylene), $5.82(\mathrm{dd}, 1 \mathrm{H}, J=10.4$ and $1.5 \mathrm{~Hz}$, ethylene), $4.18(\mathrm{t}, 2 \mathrm{H}$, $\left.-\mathrm{COOCH}_{2}-\right), 4.02\left(\mathrm{t}, 2 \mathrm{H},-\mathrm{PhOCH}_{2}-\right), 2.40\left(\mathrm{~s}, 3 \mathrm{H},-\mathrm{CH}_{3}\right)$, 1.84 (quint, $2 \mathrm{H},-\mathrm{COOCH}_{2} \mathrm{CH}_{2}$ ), 1.72 (quint, $2 \mathrm{H}$, $\left.-\mathrm{PhOCH}_{2} \mathrm{CH}_{2}-\right)$, $1.53-1.46\left(\mathrm{~m}, 4 \mathrm{H},-\mathrm{CH}_{2} \mathrm{CH}_{2} \mathrm{CH}_{2} \mathrm{CH}_{2}-\right)$ ppm. ${ }^{13} \mathrm{C}-\mathrm{NMR}\left(100 \mathrm{MHz}, \mathrm{CDCl}_{3}\right): \delta 166.3,162.1$, 161.4 , 155.3, 152.6, 130.6, 128.6, 125.5, 113.5, 112.7, $111.9,101.3,68.4,64.4,28.9,28.5,25.7,25.7,18.7 \mathrm{ppm}$.
Anal. Calcd for $\mathrm{C}_{19} \mathrm{H}_{22} \mathrm{O}_{5}$ : C, 69.07; H, 6.71. Found: C, 69.12; H, 6.77 .

\subsection{Polymerization}

Polymerization was carried out in a test tube of DMSO solution of the NIPAM and A6C or A6MC with AIBN as a radical initiator. Atmosphere of the monomer solution was substituted by nitrogen. The solution was heated at $60{ }^{\circ} \mathrm{C}$ for $2 \mathrm{~h}$ and then $80{ }^{\circ} \mathrm{C}$ for $1 \mathrm{~h}$. After polymerization, the solution was washed with water and hydrochloric acid $(1 \mathrm{mmol} / \mathrm{L})$ for several times. Molar ration was estimated by comparison with molar extinction coefficient of UV spectrum for the copolymer and that for 6-hexyloxycoumarin or 6-hexyloxy4-methylcoumarin. The synthesized copolymers are listed in Table 1.

\subsection{Instrumentation and Techniques}

Molecular weight of the copolymers were estimated by gel permeation chromatography (GPC) using a PU-2080+UV-2075+CO-2060 apparatus (JASCO) with GPC KF-804 columns (Shodex). Eluent was THF. Polystyrenes were employed as molecular weight standards. UV irradiation at $\lambda>310 \mathrm{~nm}$ was carried out by a $200 \mathrm{~W}$ high pressure Hg-Xe lamp UVF-204S (San-ei Electric) with a cold mirror and a UV-cut glass filter UV-31 (AGC Techno Glass). Irradiation at $\lambda=254$ $\mathrm{nm}$ was carried out by low-pressure $\mathrm{Hg}$ lamp with a handy lamp SLUV-41 (AS ONE). UV spectra were measured by a V-650 spectrophotometer (JASCO). Viscosity was measured by a DV-II (Brookfield). Gel strength was recorded using a Sun Science Sun Rheo Meter CR-500DX. The strength was evaluated as the force necessary to sink a cylinder bar $(\phi 5 \mathrm{~mm})$ down to a depth of $2-5 \mathrm{~mm}$ in the gel.

\section{RESULTS AND DISCUSSION}

3.1 Photodimerization of coumarin moieties monitored by UV spectroscopy

Composition molar ratio and molecular weight of the synthesized copolymers, P(NIPAM-co-A6C) and $\mathrm{P}(\mathrm{NIPAM}-$ co-A6MC) are listed in Table 1. All the copolymers can dissolve in water. We have prepared ca. $4 \mathrm{wt} \%$ aqueous solution of the copolymers and measured their UV spectra before and after UV irradiation. Fig. 2 exhibits UV spectral changes of the copolymers. Before UV irradiation, the copolymers have an absorption band ascribable to the coumarin moiety at around $320 \mathrm{~nm}$. This absorption decreases by UV $(\lambda>310 \mathrm{~nm})$ irradiation, which indicates occurring of photodimerization of coumarin moieties and generation of cyclobutane rings.

Table 1. Composition ratio and molecular weight of the copolymers.

\begin{tabular}{|c|c|c|c|c|c|}
\hline copolymer & $\begin{array}{c}\text { charged molar ratio } \\
\text { NIPAM : A6C or A6MC }\end{array}$ & $\begin{array}{c}\text { molar ratio }^{\text {a) }} \\
\text { NIPAM : A6C or A6MC }\end{array}$ & $M n / 10^{4}$ & $M w / 10^{4}$ & $M w / \mathrm{M} n$ \\
\hline P(NIPAM $\left.{ }_{100}-c o-\mathrm{A6C}_{0.3}\right)$ & $100: 0.3$ & $100: 0.24$ & 4.4 & 5.2 & 1.2 \\
\hline P(NIPAM $\left.{ }_{100}-c o-A 6 M_{0.3}\right)$ & $100: 0.3$ & $100: 0.27$ & 1.8 & 3.4 & 1.9 \\
\hline P(NIPAM $\left.100-c o-A 6 M_{1}\right)$ & $100: 1$ & $100: 1.1$ & 0.84 & 1.3 & 1.5 \\
\hline
\end{tabular}

a) Estimated by UV absorption of coumarin or 4-methylcoumarin moieties. 
Subsequent UV $(\lambda=254 \mathrm{~nm})$ irradiation restores this absorption band by ca. $60 \%$. The cyclobutane rings cleave and return to coumarin structures by UV $(\lambda=254)$ irradiation. In this case, ca. $90 \%$ of coumarins dimerized photochemically and ca. $60 \%$ of dimmers return to the coumarins.
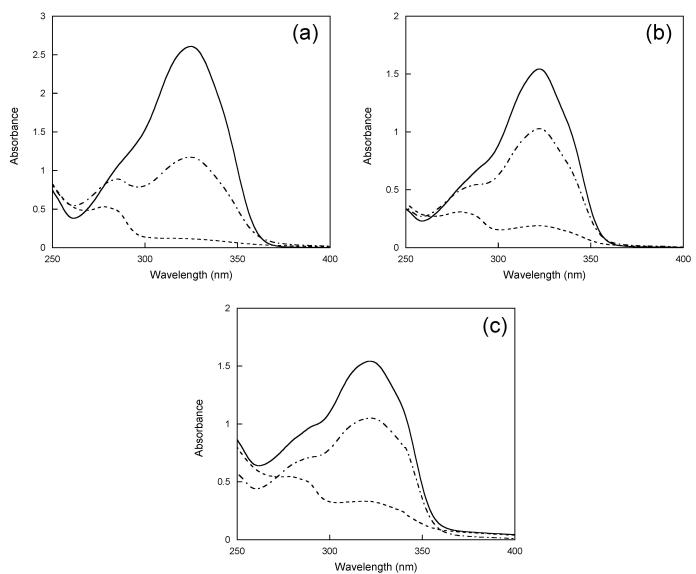

Fig.2 UV spectral changes of the aqueous solutions. (a) $4.4 \mathrm{wt} \%$ of $\mathrm{P}\left(\mathrm{NIPAM} 100-c o-\mathrm{A}_{6} \mathrm{C}_{0.3}\right)$, solid line: before irradiation, dashed line: after UV $(\lambda>310 \mathrm{~nm})$ irradiation for $30 \mathrm{~min}$, dashed-dotted line: after prolonged UV $(\lambda=254 \mathrm{~nm})$ irradiation for $40 \mathrm{~min}$. (b) $4.7 \mathrm{wt} \%$ of $\mathrm{P}\left(\mathrm{NIPAM} \mathrm{M}_{100}-\mathrm{co}-\mathrm{A} 6 \mathrm{MC}_{0.3}\right)$, solid line: before irradiation, dashed line: after UV $(\lambda>310 \mathrm{~nm})$ irradiation for $30 \mathrm{~min}$, dashed-dotted line: after prolonged $\operatorname{UV}(\lambda=254 \mathrm{~nm})$ irradiation for $20 \mathrm{~min}$. (c) $4.0 \mathrm{wt} \%$ of $\mathrm{P}\left(\mathrm{NIPAM}_{100}-\mathrm{co}-\mathrm{A} 6 \mathrm{MC}_{1}\right)$, solid line: before irradiation, dashed line : after $U V(\lambda>310 \mathrm{~nm})$ irradiation for $20 \mathrm{~min}$, dashed-dotted line: after prolonged UV $(\lambda=254 \mathrm{~nm})$ irradiation for $20 \mathrm{~min}$.

\subsection{Photoinduced sol-gel conversion}

We have examined macroscopic changes in the copolymer solutions caused by the photodimerization and photocleavage of coumarin moieties. Fig. 3 exhibits the photographs of the copolymer solutions before and after UV irradiations. All the solution loses fluidity and change to hydrogels after UV $(\lambda>310 \mathrm{~nm})$ irradiation, although they have fluidity before irradiation. Subsequent UV $(\lambda=254 \mathrm{~nm})$ irradiation of $\mathrm{P}\left(\mathrm{NIPAM} 100-c o-\mathrm{A}_{60.3}\right)$ and $\mathrm{P}\left(\mathrm{NIPAM} \mathrm{M}_{100}-c o-\mathrm{A}_{0} \mathrm{MC}_{0.3}\right)$ induces the gel-to-sol conversion and their fluidity reforms. This gel-to-sol conversion repeats at least two times. The reversible intermolecular photodimerization and photocleavage of coumarin moieties by UV irradiation can construct and break crosslinks of the copolymers as shown in Fig. 4. The gel state, however,

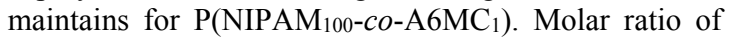
the coumarin moieties is important for macroscopic reversible conversion between gel and sol state. For the hydrogel containing coumarin moiety larger than 1 mol\%, the coumarin dimer structure (=cyclobutane structure), crosslink moiety remains enough to keep the gel state under UV $(\lambda=254 \mathrm{~nm})$ irradiation. Because the dimeric cyclobutane structure cannot completely return to the monomer coumarin by UV $(\lambda=254 \mathrm{~nm})$ irradiation even though the irradiation is prolonged.
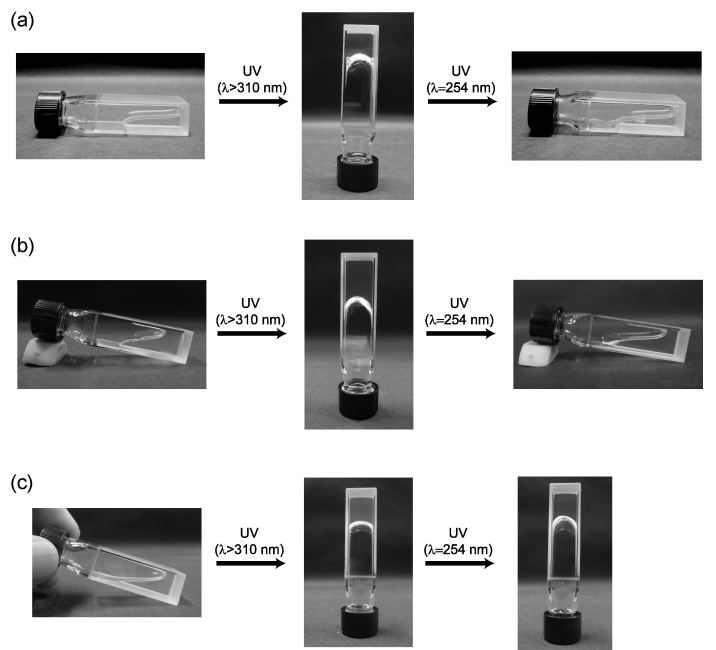

Fig.3 Photoinduced conversion of the hydrogels in 1-cm width spectroscopic quartz cell. (a) P(NIPAM $100-c o-\mathrm{A}_{6 \mathrm{C}_{0.3}}$ ). (b) P(NIPAM $\left.100-c o-\mathrm{A}_{6} \mathrm{MC}_{0.3}\right)$. (c) P(NIPAM $\left.100-c o-A 6 \mathrm{MC}_{1}\right)$.

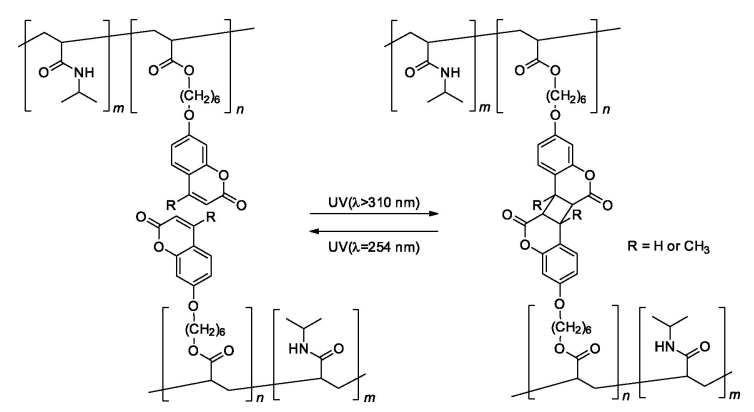

Fig.4 Photoinduced crosslinking and cleavage of the copolymers.

\subsection{Photoinduced viscosity changes}

We have examined viscosity of P(NIPAM ${ }_{100}-$ co-A6 $\mathrm{MC}_{0.3}$ ) before and after irradiations. Before irradiation, the copolymer solution exhibits low viscosity and behaves as almost Newtonian fluid, shown in Fig.5 (closed circles). UV $(\lambda>310 \mathrm{~nm})$ irradiation of the aqueous solutions for the copolymers causes the increase in viscosity based on photodimerization of coumarin moieties (open circles). This gel exhibits non-Newtonian behavior. Subsequent irradiation with UV $(\lambda=254 \mathrm{~nm})$ light of the hydrogels decreases viscosity, inducing the change to the sol from the gel. UV $(\lambda>310 \mathrm{~nm})$ irradiation of this sol restores high viscosity.

The mechanical strength of the solution of $\left.\mathrm{P}_{(\mathrm{NIPAM}} \mathrm{A0}_{10} c 0-\mathrm{A} 6 \mathrm{MC}_{0.3}\right)$ before UV irradiation was lower than the measurement limit. After $\operatorname{UV}(\lambda>310 \mathrm{~nm})$ irradiation of the solution, the gel strength became $30 \pm$ 
$4 \mathrm{~g} / \mathrm{cm}^{2}$. After subsequent UV $(\lambda=254 \mathrm{~nm})$ irradiation, the strength cannot be measured because of low measurement limit.

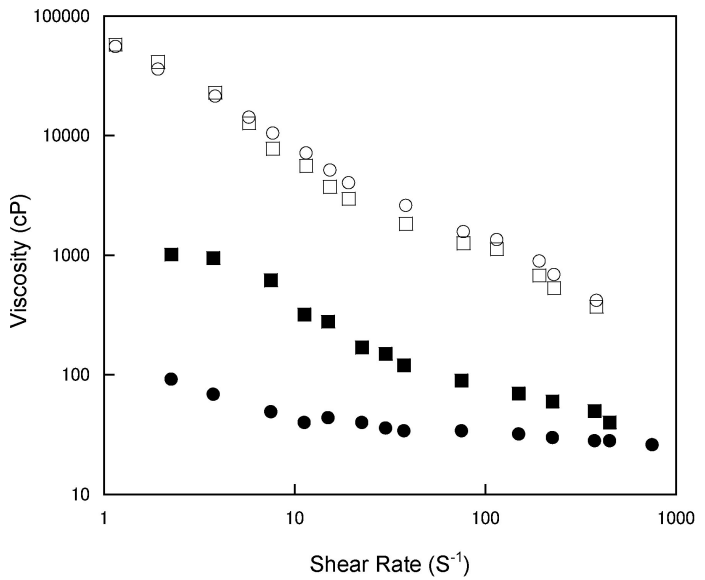

Fig.5 Viscosity change of hydrogel consisting of P(NIPAM $\left.100-c o-A 6 M_{0.3}\right)$. Closed circles: before irradiation, open circles: after UV $(\lambda>310 \mathrm{~nm})$ irradiation for $20 \mathrm{~min}$, closed squares: after prolonged UV $(\lambda=254$ $\mathrm{nm})$ irradiation for $20 \mathrm{~min}$, open squares : after UV $(\lambda=254 \mathrm{~nm})$ irradiation for $20 \mathrm{~min}$.

\section{COCLUSION}

We have prepared three hydrophilic copolymers containing $N$-isopropylacrylamide and acrylate with coumarin or 4-methylcoumarin moieties; $\mathrm{P}\left(\mathrm{NIPAM}_{100}-c o-\mathrm{A}_{6 \mathrm{C}} \mathrm{C}_{0.3}\right), \quad \mathrm{P}\left(\mathrm{NIPAM}_{100}-c o-\mathrm{A}_{6} \mathrm{MC}_{0.3}\right)$, and $\mathrm{P}\left(\mathrm{NIPAM} \mathrm{AM}_{100}-\mathrm{co}-\mathrm{A} 6 \mathrm{MC}_{1}\right)$. UV light $(\lambda>310 \mathrm{~nm})$ irradiation of aqueous solutions for the copolymers causes the increase in viscosity and the formation of hydrogels, based on photodimerization of coumarin moieties. Subsequent irradiation with UV light $(\lambda=254$ $\mathrm{nm})$ of the hydrogels of P(NIPAM $\left.100-c o-\mathrm{A}_{6} \mathrm{C}_{0.3}\right)$, and $\mathrm{P}\left(\mathrm{NIPAM}_{100}-\mathrm{co}-\mathrm{A} 6 \mathrm{MC}_{0.3}\right)$ induces return of fluidity and the change to sol state, due to the decomposition of coumarin dimers. A very small content of coumarin and 4-methylcoumarin units is important for macroscopic photoinduced and reversible sol-gel conversions. The amount of crosslink structures in the copolymers can be regulated by the reversible photoreaction of coumarin moieties.

\section{ACKNOWLEDGEMENT}

The authors would like to acknowledge Prof. Yuichi Ishikawa and Dr. Kaoru Nobuoka for viscosity measurement, and Mrs. Ayako Sato of A-Rabbit-Science Japan Co.,Ltd. for elemental analysis.

\section{REFERENCES}

[1] Y. Chujo, K. Sada, and T. Saegusa, Macromolecules, 23, 2693-2697 (1990).

[2] J. He, X. Tong, and Y. Zhao, Macromolecules, 42, 4845-4852 (2009).

[3] J. Jiang, B. Qi, M. Lepage, and Y. Zhao, Macromolecules, 40, 790-792 (2007).
[4] J. Babin, M. Lepage, and Y. Zhao, Macromolecules, 41, 1246-1253 (2008).

[5] Y. Zhao, L. Tremblay, Y. Zhao, Macromolecules, 44, 4007-4011 (2011).

[6] J. He, B. Yan, L. Tremblay, and Y. Zhao, Langmuir, 27, 436-444 (2011).

[7] R. H. Huyck, S. R. Trenor, B. J. Love, and T. E. Long, J. Macromol. Sci., Part A: Pure\&Appl. Chem., 45 , 9-15 (2008).

[8] Y. Chen and J.-L. Geh, Polymer, 37, 4473-4480 (1996).

[9] T. Ngai and C. Wu, Macromolecules, 36, 848-854 (2003).

[10] P. O. Jackson and M. O'Neill, Chem. Mater., 13, 694-703 (2001).

[11] J. Jiang, Q. Shu, X. Chen, Y. Yang, C. Yi, X. Song, X. Liu, and M. Chen, Langmuir, 26, 14247-14254 (2010).

[12] M. V. S. N. Maddipatla, D. Wehrung, C. Tang, W. Fan, M. O. Oyewumi, T. Miyoshi, A. Joy, Macromolecules, 46, 5133-5140 (2013).

[13] E. Sato, S. Nagai, A. Matsumoto, Prog. Org. Coat., 76, 1747-1751 (2013).

[14] H. Ajiro and M. Akashi, Chem. Lett., 43, 1613-1615 (2014).

[15] M. Obi, S. Morino, and K. Ichimura, Chem. Mater., 11, 656-664 (1999).

[16] M. J. Brites, C. Santos, S. Nascimento, B. Gigante, H. Luftmann, A. Fedorov, and M. N. Berberan-Santos, New J. Chem., 30, 1036-1045 (2006).

(Received February 17, 2015; Accepted March 15, 2015) 